\title{
3D Structures in Battery Materials
}

\author{
Johannes PROELL ${ }^{* 1}$, Robert KOHLER ${ }^{* 1}$, Alexander MANGANG ${ }^{* 1}$, Sven ULRICH ${ }^{* 1}$, Carlos ZIEBERT ${ }^{* 1}$, \\ Wilhelm PFLEGING ${ }^{* 1, * 2}$ \\ ${ }^{* 1}$ Karlsruhe Institute of Technology, IAM-AWP, P.O. Box 3640, 76021 Karlsruhe, Germany \\ E-mail: johannes.proell@kit.edu \\ ${ }^{* 2}$ Karlsruhe Nano Micro Facility, H.-von-Helmholtz-Platz 1, 76344 Egg.-Leopoldshafen, Germany
}

\begin{abstract}
Efficient lithium-ion batteries will play an important role within the development of future mobile and stationary applications such as portable microsystems, high power electric vehicles or high energy storage devices. All applications strongly require an improvement of the materials used in electrochemical cells in order to increase stability, power and energy density as well as cell lifetime. To challenge this demand, the development of future cell systems is mainly focused on the composition of solid electrolytes as well as on powerful rechargeable lithium-ion intercalation electrodes consisting out of nano-composite materials. In this work, thin film electrodes based on lithium manganese oxide compounds were deposited by radiofrequency magnetron sputtering on steel and silicon substrates. Within a new technical approach, UV-laser process technologies using a wavelength of $248 \mathrm{~nm}$ were applied in order to form three-dimensional cathode structures. Rapid laser annealing processes operating at $940 \mathrm{~nm}$ were performed to adjust an appropriate crystalline phase. Phase and structural analysis was performed using Raman spectroscopy, X-ray diffraction and electrochemical testing. The principle set-up of a three-dimensional all-solid state cell was shown by sputtering of lithium vanadium silicon oxide electrolyte and aluminium anode material on top of the lithium manganese oxide 3D structures. DOI:10.2961/jlmn.2012.01.0019
\end{abstract}

Keywords: Lithium-ion battery, lithium manganese oxides, laser structuring, laser annealing, cathode material, all-solid state batteries, lithium vanadium silicon oxide

\section{Introduction}

The development of 3-dimensional (3D) cell architectures for electrodes for lithium-ion batteries is one promising approach to overcome problems like 1-dimensional Liion diffusion, inhomogeneous current densities, power losses, high interelectrode ohmic resistance [1] as well as mechanical stresses due to high volume changes resulting from Li-ion insertion [2]. New cell designs and manufacturing methods are required e.g. for applications in microelectronic devices [3] or microelectromechanical systems (MEMS) [1]. Therefore, especially cathodes are required which show good electrochemical performance and, depending on the synthesizing route, good Li-ion diffusion properties. Material requirements for the cathode are well nano-crystallized phases, phase stability during the charging and discharging process, low costs and non-toxicity. The latter fact can be achieved using cathodes based on lithium manganese oxygen compounds ( $\mathrm{Li}-\mathrm{Mn}-\mathrm{O})$ which are strong competitors concerning costs and environmental safety [4] in comparison to cobalt or nickel based intercalation cathodes [5,6]. Disadvantages of Li-Mn-O cathode materials are the suffering from phase instabilities and phase changes induced through Jahn-Teller distortion and electrochemical cycling $[7,8]$, chemical degradation effects such as loss of active material by chemical reaction with the liquid electrolyte [9] as well as destabilization of the electrode when operating the electrochemical cell near or below the $3 \mathrm{~V}$ region [7]. The understanding and control of mechanisms of formation and stability of the Solid Electrolyte Interphase (SEI) is one of the most important issues in development of advanced electrodes. Therefore, one future challenge is to understand and analyze the cycling behavior of the synthesized manganese based cathode compound and to set-up new 3D cell designs which may be integrated into micro-devices. One new process is to pattern radiofrequency (rf) magnetron sputtered thin films by a direct laser patterning process in order to increase the active surface and to provide faster Li-ion diffusion which has already been demonstrated in the past for several thin film electrode materials [2,10-14]. Another promising approach to get rid of thickness limitations and to form defined patterns is the laser direct-write (LDW) technique where electrode materials are printed on substrates and can therefore form user-defined patterns [3] as well as the laser induced forward transfer (LIFT) technique e.g. to integrate power sources into an electronic device [15].

\section{Experimental section}

\subsection{Electrode and electrolyte thin film deposition}

Thin films in the Li-Mn-O system were grown on stainless steel (diameter $12 \mathrm{~mm})$ and silicon (100) (area $1 \mathrm{~cm}^{2}$ ) substrates by non-reactive rf magnetron sputtering using a Leybold Z550 coating facility. The deposition atmosphere was pure argon. The $\mathrm{LiMn}_{2} \mathrm{O}_{4}$ target from MaTeck $\mathrm{GmbH}$ had a diameter of 3 inches and a thickness of 0.25 inches. The purity was determined to be $99.9 \%$. The target and the substrate plate had a distance of $6 \mathrm{~cm}$. The target power was $200 \mathrm{~W}$ and the working gas pressure was set to $0.25 \mathrm{~Pa}$. Before thin film deposition, the substrates were ultrasonically cleaned in acetone and isopropanol each for $15 \mathrm{~min}$ and were afterwards plasma-etched in argon for $15 \mathrm{~min}$. 
The thickness of the as-deposited thin films was in the range of $2-3.3 \mu \mathrm{m}$ depending on the location on the substrate plate during deposition and was measured using a surface profilometer. The maximum thin film growth rate was calculated to be $13.3 \mathrm{~nm} / \mathrm{min}$.

A Lithium vanadium silicon oxide (LVSO) thin film electrolyte was deposited on top of the laser structured Li$\mathrm{Mn}-\mathrm{O}$ cathode with the grating pattern at a power of $150 \mathrm{~W}$ and a pressure during deposition of $0.5 \mathrm{~Pa}$. A circular segmented target was used composed of $\mathrm{V}_{2} \mathrm{O}_{5} / \mathrm{Li}_{4} \mathrm{SiO}_{4}$ (Kurt J. Lesker Company Ltd. / MaTeck $\mathrm{GmbH}$ ) ceramic half plates and the laser structured Li-Mn-O cathode was positioned centrally below the $\mathrm{Li}_{4} \mathrm{SiO}_{4}$ part of the segmented target because solid state electrolyte films with the composition $\mathrm{Li}_{1.2} \mathrm{~V}_{1.3} \mathrm{Si}_{0.7} \mathrm{O}_{4}$ that develops at this position has shown the highest ionic conductivity of $6.5 \times 10^{-5} \mathrm{~S} / \mathrm{cm}$ [16]. Aluminium (Goodfellow $\mathrm{GmbH}$ ) as the anode was sputtered at $50 \mathrm{~W}$ under $0.5 \mathrm{~Pa}$ working pressure.

\subsection{Reference powder}

Lithium manganese(III,IV) oxide powder (SigmaAldrich) was used as a reference material for Raman spectroscopy and X-ray diffraction measurements of the Li-Mn$\mathrm{O}$ thin films. The purity of the powder was $>99 \%$ and the particle size $<0.5 \mu \mathrm{m}$ (BET, [17]) while the density was specified to be $4.1 \mathrm{~g} / \mathrm{cm}^{3}$ at $25^{\circ} \mathrm{C}$.

\subsection{Laser structuring and -annealing processes}

Thin film laser structuring was performed using a short pulse excimer laser (ATLEX-500-SI, ATL Lasertechnik $\mathrm{GmbH}$ ). The operation wavelength was $\lambda=248 \mathrm{~nm}$ and the repetition rate could be adjusted in the range of $1-500 \mathrm{~Hz}$. At FWHM the laser pulse length counted $4-6$ ns. The raw beam reveals a rectangular intensity profile and chromium/quartz mask techniques could be implemented for large area direct laser patterning of the Li-Mn-O thin films. Therefore, a chromium coated suprasile ${ }^{\circledR}$ type quartz glass was used. The objective lens had a demagnification factor of $1: 10$ and the maximum laser fluence was determined to be $5 \mathrm{~J} / \mathrm{cm}^{2}$ on the sample surface. The laser fluence could be controlled via a motorized beam attenuator. Heat treatment of the Li-Mn-O thin films was achieved by laser annealing using a high power diode laser system (FLS IronScan, Fisba Optik AG) operating at a wavelength of $\lambda=940 \mathrm{~nm}$. The diameter of the laser beam in focus was $1 \mathrm{~mm}$ and the annealing temperature was controlled on-line by a pyrometer (FLS PyroS, Fisba Optik AG). The adjustment control for constant temperature was realized within an adjustment time of $1 \mathrm{~ms}$. The temperature could be varied in the range of $120-700{ }^{\circ} \mathrm{C}$.

\subsection{Phase, structure and morphology analysis}

Micro-Raman spectroscopy was performed for Li-Mn$\mathrm{O}$ phase analysis of the thin films and reference powder. The measurements were done with a Renishaw-1000 system equipped with an argon-ion laser (excitation wavelength $\lambda=514.5 \mathrm{~nm}$, power output $\mathrm{P}=23 \mathrm{~mW}$ ). The output power was reduced to $10 \%$ in order to avoid decomposition or annealing of the materials.

Structural analysis was investigated using X-ray diffraction (type Seifert PAD II, Bragg-Brentano arrangement, $\mathrm{Cu} \mathrm{K} \alpha 1$ radiation, $\lambda=0.154 \mathrm{~nm}$ ).
The surface morphology of the laser structured and laser annealed $\mathrm{Li}-\mathrm{Mn}-\mathrm{O}$ thin films was performed using a scanning electron microscope (Philips XL 30S).

\subsection{Cell fabrication and electrochemical testing}

Test cells were set-up in an argon-filled glove box (LABmaster sp, M. Braun Inertgas-Systeme $\mathrm{GmbH}$ ) using the Swagelok ${ }^{\circledR}$ geometry. Therefore, a laser-annealed Li$\mathrm{Mn}-\mathrm{O}$ thin film (substrate area $1.131 \mathrm{~cm}^{2}$ ) was used as cathode and lithium metal was applied as counter electrode for both, galvanostatic testing and cyclic voltammetry (CV). Liquid electrolyte composed out of a solvent mixture of ethylene carbonate and dimethyl carbonate (EC/DMC) in a ratio of $1: 1$ containing $1 \mathrm{M}$ lithium hexafluorophosphate $\left(\mathrm{LiPF}_{6}\right)$ as conducting salt was used as well as one layer of glass microfiber separator (GF/A filter, thickness $260 \mu \mathrm{m}$, whatman company). Electrochemical cycling as well as CV was performed using an Arbin Instruments BT2000 testing system. In order to match a specific C-rate, the practical capacity of about $110 \mathrm{mAh} / \mathrm{g}$ for $\mathrm{LiMn}_{2} \mathrm{O}_{4}$ in the range of $3.0-4.2 \mathrm{~V}$ [8] was assumed in order to define a constant current for charging and discharging the test cell. Therefore, the C-rate is defined as the ratio of discharge current to capacity $[\mathrm{A} / \mathrm{Ah}=1 / \mathrm{h}]$ and describes the duration of one half-cycle. Considering a Li-Mn-O thin film density of $4.02 \mathrm{~g} / \mathrm{cm}^{3}$ [14] after rf magnetron sputtering, the constant dis-/charging current could be calculated to be $27.06 \mu \mathrm{A}$ (C-rate of $\mathrm{C} / 5$ ) taking into account the thin film mass and practical capacity.

$\mathrm{CV}$ scans were recorded between $2.5-4.3 \mathrm{~V}$ as well as between 3.0 - $4.3 \mathrm{~V}$ using a constant $0.02 \mathrm{mVs}^{-1}$ sweep rate for all measurements.

\section{Results and discussion}

The formation of three-dimensional surface structures in Li-Mn-O thin films requires the application of chromium/quartz mask techniques for direct patterning of the cathode because self-organized formation of 3D structures due to UV-laser irradiation of the thin film does not take place, e.g. like cone growth in $\mathrm{LiCoO}_{2}$ thin films [11-13]. For using the direct laser patterning process for asdeposited Li-Mn-O thin films two different mask patterns were investigated, schematically shown in Fig. 1.

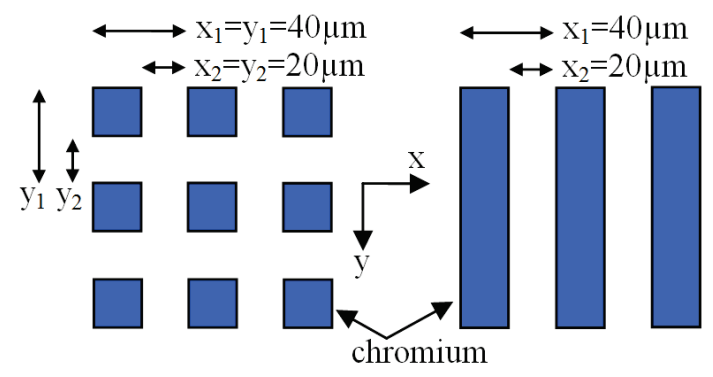

Fig. 1 Schematic design of the arrangement of patterns on chromium/quartz masks used for UV-laser structuring of Li-Mn$\mathrm{O}$ thin films (left: $40 / 20 \mu \mathrm{m}$ grating pattern, right: $40 / 20 \mu \mathrm{m}$ line pattern) 
The dimensions on the mask for the grating pattern (Fig. 1 , left) show quadratic chromium areas with a width of $20 \mu \mathrm{m}$ and a pitch of $40 \mu \mathrm{m}$ from edge to edge of two such areas in each direction. In order to form narrow channels within the material, a mask with a line pattern was applied also showing a width of $20 \mu \mathrm{m}$ of the chromium areas and a line-to-line pitch of $40 \mu \mathrm{m}$ (Fig. 1, right).

Fig. 2 shows the result for the laser patterning process using the grating mask depicted in Fig. 1, left. Spherical surface structures were formed with smooth surfaces and without any debris. Slight solidification boundaries were detected on the structured surfaces but they disappear within the subsequent annealing process as shown by Fig. 4, where a linking of grains is detected. Laser ablation was performed under ambient air using a laser fluence of $\varepsilon=1.6 \mathrm{~J} / \mathrm{cm}^{2}, \mathrm{~N}=60$ laser pulses and a repetition rate of $v_{\text {rep }}=100 \mathrm{~Hz}$.

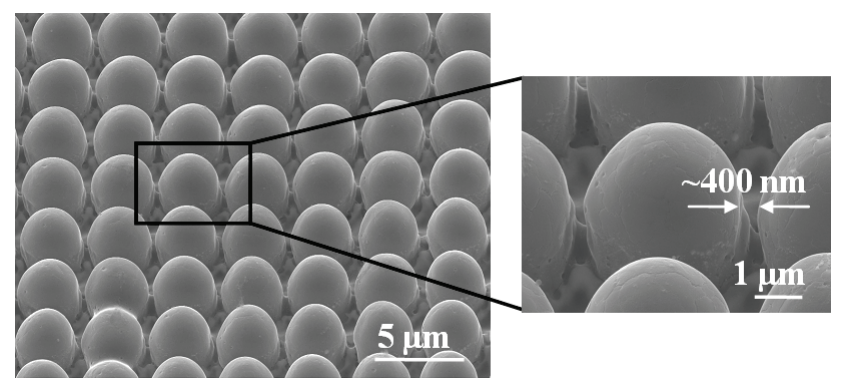

Fig. 2 Spherical 3D surface structures formed via UV-laser structuring of Li-Mn-O thin films using chromium/quartz mask technique and the $40-20 \mu \mathrm{m}$ grating pattern $(\lambda=248 \mathrm{~nm}$, energy density $\varepsilon=1.6 \mathrm{~J} / \mathrm{cm}^{2}$, pulse number $\mathrm{N}=60$, repetition rate $v_{\text {rep }}=100 \mathrm{~Hz}$, ambient air).

Within the use of the line patterned mask high aspect ratio structures (of up to 5) could be formed. Fig. 3 shows line structures with channel widths of about $400 \mathrm{~nm}$ using $1.6 \mathrm{~J} / \mathrm{cm}^{2}, 60$ laser pulses and $100 \mathrm{~Hz}$. Considering the numerical aperture of the objective $(\mathrm{NA}=0.105)$ and the laser wavelength of $\lambda=248 \mathrm{~nm}$, the minimum distance $\mathrm{d}$ in between two distinguishable structures can be calculated out from Eq. 1 as follows:

$$
\mathrm{d}=\lambda /(2 \mathrm{NA})=1.18 \mu \mathrm{m}
$$

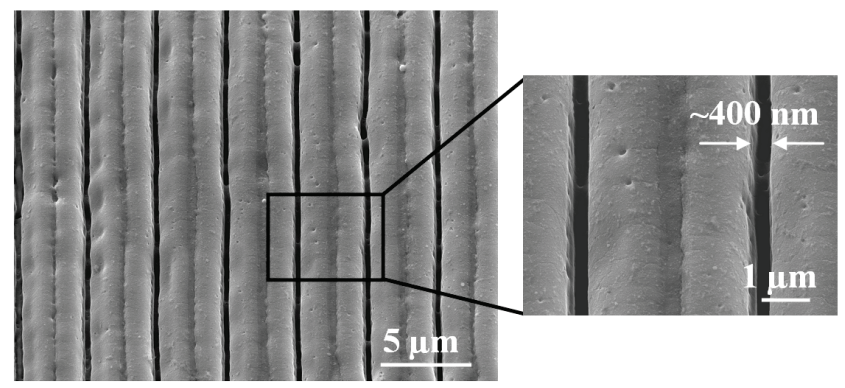

Fig. 3 Line structures formed via UV-laser structuring of Li$\mathrm{Mn}-\mathrm{O}$ thin films using chromium/quartz mask technique and the 40 - $20 \mu \mathrm{m}$ line pattern $\left(\lambda=248 \mathrm{~nm}\right.$, energy density $\varepsilon=1.6 \mathrm{~J} / \mathrm{cm}^{2}$, pulse number $\mathrm{N}=60$, repetition rate $v_{\text {rep }}=100 \mathrm{~Hz}$, ambient air).

Taking into account the mask structure dimensions and the objective demagnification of 1:10 it is obvious that the minimal feature sizes e.g. the channel width should count $2 \mu \mathrm{m}$. Due to this fact, it is obvious that diffraction effects play an important role during the laser irradiation process getting more pronounced when increasing the laser fluence $\varepsilon$ and therefore, feature sizes below the calculated theoretical minimum were achieved. This process can be described as multiple beam interference very similar to the laser patterning process obtained with phase shift masks [18] where structure sizes down to $200-400 \mathrm{~nm}$ can be achieved.

Laser annealing processes for cathode thin films composed out of Li-Mn-O [14] or $\mathrm{LiCoO}_{2}[11,13]$ represent a powerful tool for setting-up an appropriate crystalline phase which is electrochemically active. The main advantages compared to conventional furnace annealing are reduced processing times (seconds instead of hours) and the precise control of grain sizes as a function of annealing time and temperature $[11,14]$. The latter fact is depicted in Fig. 4. While the grains grown by laser-annealing (Fig. 4, a) show a prismatic topography with linking in between the grains and sizes up to $250 \mathrm{~nm}$ in lateral expansion, the grains obtained through furnace annealing for three hours at $700{ }^{\circ} \mathrm{C}$ are significantly larger $(\sim 500 \mathrm{~nm})$ and form a craggy surface due to inhomogeneous grain orientation and size.
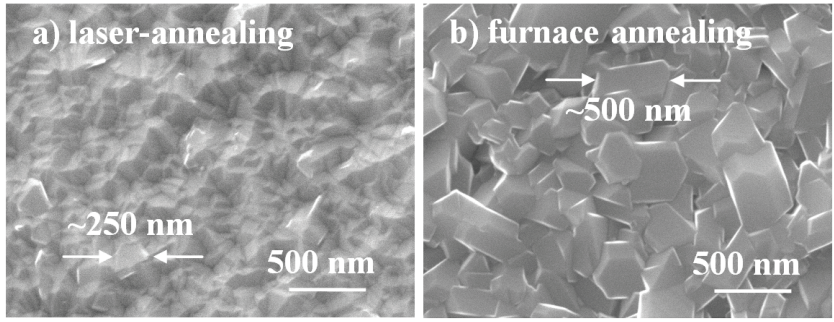

Fig. 4 SEM top view images of (a) laser-annealed and (b) furnace annealed $\mathrm{Li}-\mathrm{Mn}-\mathrm{O}$ thin films showing the grain sizes and grain structure. Laser-annealing was performed within $t=100 \mathrm{~s}$, $\mathrm{T}=680^{\circ} \mathrm{C}$ under ambient air while furnace annealing was set-up for three hours at $\mathrm{T}=700{ }^{\circ} \mathrm{C}$ under ambient air.

Rapid laser-annealing methods were applied as thermal treatment process of the as-deposited Li-Mn-O thin films in order to form a crystalline phase. Therefore, within an annealing time of $\mathrm{t}=100 \mathrm{~s}$, a laser scanning velocity of $\mathrm{v}=1000 \mathrm{~mm} / \mathrm{s}$ and an average annealing temperature of $\mathrm{T}=680^{\circ} \mathrm{C}$ a spinel-like phase could be achieved. Fig. 5 shows both, the Raman spectra for the $\mathrm{LiMn}_{2} \mathrm{O}_{4}$ reference powder (a) as well as for the laser-annealed $\mathrm{Li}-\mathrm{Mn}-\mathrm{O}$ thin film (b). A broad peak at $625 \mathrm{~cm}^{-1}$ can be detected out from Fig. 5, b indicating the $\mathrm{A}_{1 \mathrm{~g}}$ symmetry which corresponds to a stretching vibration of manganese and oxygen compounds within the $\mathrm{MnO}_{6}$ octahedra and it is broad due to a variation of the binding lengths of anions and cations within the structure [19]. The corresponding peak of the reference powder has its maximum at a slightly higher wave number of $635 \mathrm{~cm}^{-1}$ (Fig. 5, a). The low intensity shoulder coming up at $583 \mathrm{~cm}^{-1}\left(\mathrm{~F}_{2 \mathrm{~g}}\right.$ species $)$ is supposed to be linked to the averaged manganese oxidation state. This would consider the feature of the spinel structure that isotropic $\left[\mathrm{Mn}^{4+}\right] \mathrm{O}_{6}$ and Jahn-Teller distorted $\left[\mathrm{Mn}^{3+}\right] \mathrm{O}_{6}$ octahedra exist side by side. For both, the thin film and the reference powder a weak Raman band at $483 \mathrm{~cm}^{-1}$ can also be 
detected and assigned to $\mathrm{F}_{2 \mathrm{~g}}$ species $(v \mathrm{Mn}-\mathrm{O})$ of the spinel phase [19]. Nevertheless, high temperature $\left(\mathrm{T}>600^{\circ} \mathrm{C}\right)$ annealing was preferred to overcome the electrochemical inactive $\mathrm{Li}_{2} \mathrm{MnO}_{3}$ phase [20] which develops around $\mathrm{T}=600{ }^{\circ} \mathrm{C}[14]$.

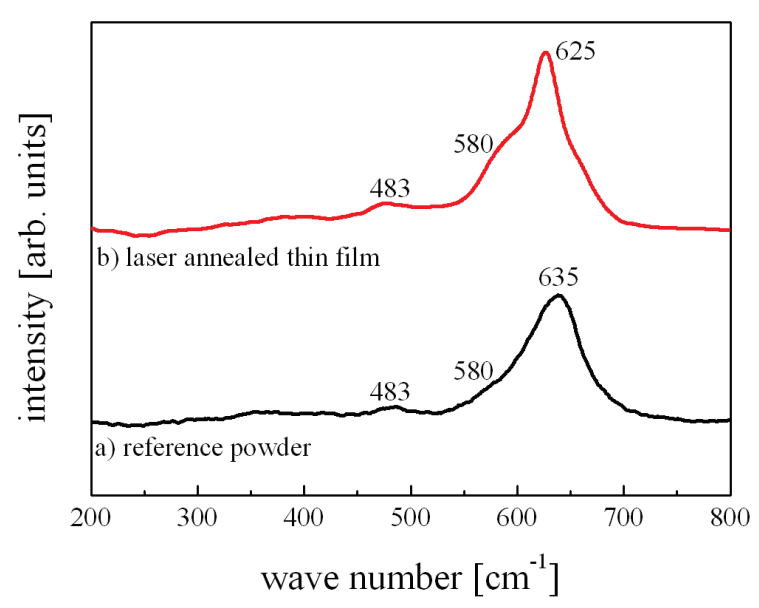

Fig. 5 Raman spectra of (a) spinel $\mathrm{LiMn}_{2} \mathrm{O}_{4}$ reference powder and (b) a laser-annealed Li-Mn-O thin film $(\lambda=940 \mathrm{~nm}$, $\mathrm{t}=100 \mathrm{~s}, \mathrm{~T}=680{ }^{\circ} \mathrm{C}$, laser scanning velocity $\mathrm{v}=1000 \mathrm{~mm} / \mathrm{s}$, ambient air).

When considering an atomic ratio of as-deposited Li$\mathrm{Mn}-\mathrm{O}$ thin films of $\mathrm{Li}: \mathrm{Mn}: \mathrm{O}=1: 1.71: 3.41$ [14] a $\mathrm{Li} /(\mathrm{Li}+\mathrm{Mn})$ ratio can be calculated leading to a value of $\mathrm{Li} /(\mathrm{Li}+\mathrm{Mn})=0.369$. Assuming that no mass losses occur during the annealing process at $\mathrm{T}=680{ }^{\circ} \mathrm{C}$ [21] one can suggest, that this compound is located within the cubic spinel region $\left(\mathrm{Li}_{1+\mathrm{x}} \mathrm{Mn}_{2-\mathrm{x}} \mathrm{O}_{4}, 0<\mathrm{x}<1 / 3\right)$ of the second kind phase diagram in air reported by Paulsen and Dahn [22]. However, this suggestion would desire for oxygen integration during the laser-annealing process under ambient air and an enrichment of lithium. It is not yet clear, if laserannealing may lead to such a desired atomic ratio located directly within or slightly besides this specific spinel region and forms a thermodynamically stable or unstable phase.

$\mathrm{X}$-ray diffraction analysis of spinel powder as well as of an annealed thin film is shown in Fig. 6. The XRD pattern of the powder (Fig. 6, a) is in good agreement with the results reported by Julien and Massot [7] and Kitamura et al. [23] for spinel $\mathrm{LiMn}_{2} \mathrm{O}_{4}$ (space group: $\mathrm{Fd} 3 \mathrm{~m}$ ). Miller indices were determined out from [24] and [5] and assigned to the powder diffraction pattern. Concerning the laserannealed thin film, not all of the powder reflexes can be observed and some show slight peak shifting compared to the powder pattern. This may result from differences in stoichiometry and therefore, in a varying of the lattice constant a. Already Paulsen and Dahn [22] reported, that the $\mathrm{Li}: \mathrm{Mn}$ ratio takes influence on the lattice constant a of the cubic spinel. Regarding a Li:Mn ratio of e.g. $\sim 0.58$, the lattice constant counts approximately $\mathrm{a}=8.205 \AA$ which is below the value of a stoichiometric compound of $\mathrm{a}=8.245 \AA[7,25]$. The diffraction pattern of $\mathrm{LiMn}_{2} \mathrm{O}_{4}$ thin film prepared by $\mathrm{rf}$ magnetron sputtering reported by Xie et al. [26] does also show preferred reflexes. Indeed, it seems that laser-annealing leads to a diffraction pattern with a dominant peak close to the (440) reflex indicating a main texture within the thin film.

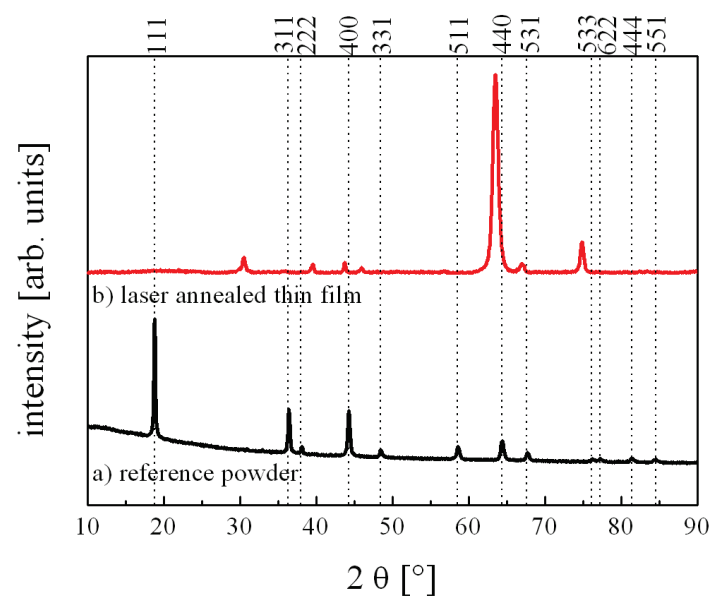

Fig. 6 X-ray diffraction patterns of (a) spinel $\mathrm{LiMn}_{2} \mathrm{O}_{4}$ reference powder and (b) a laser-annealed Li-Mn-O thin film $\left(\lambda=940 \mathrm{~nm}, \mathrm{t}=100 \mathrm{~s}, \mathrm{~T}=680^{\circ} \mathrm{C}\right.$, laser scanning velocity $\mathrm{v}=1000 \mathrm{~mm} / \mathrm{s}$, ambient air).

Fig. 7 shows a schematic view of a cross section through an ideal cubic lattice (space group: Fd3m [19]) of the $\mathrm{LiMn}_{2} \mathrm{O}_{4}$ spinel phase which exposes the (440) lattice plane parallel to surface and resulting $\mathrm{Li}^{+}$sites with vacancies. A cubic spinel phase was assumed, inheriting constant lattice parameters $\mathrm{a}=\mathrm{b}=\mathrm{c}=8.245 \AA[7,25]$. In this view, lithium on $8 \mathrm{a}[19,27]$ Wyckoff sites, vacancies on $16 \mathrm{c}$ Wyckoff sites and the resulting Li-ion diffusion paths in red are depicted while manganese on 16d [19,27] and oxygen on $32 \mathrm{e}[19,27]$ sites are not presented in this view. It is suggested, that a similar specific orientation as a dominant texture was obtained through laser-annealing of Li-Mn-O thin films at $\mathrm{t}=100 \mathrm{~s}, \mathrm{~T}=680{ }^{\circ} \mathrm{C}$ and under ambient air.

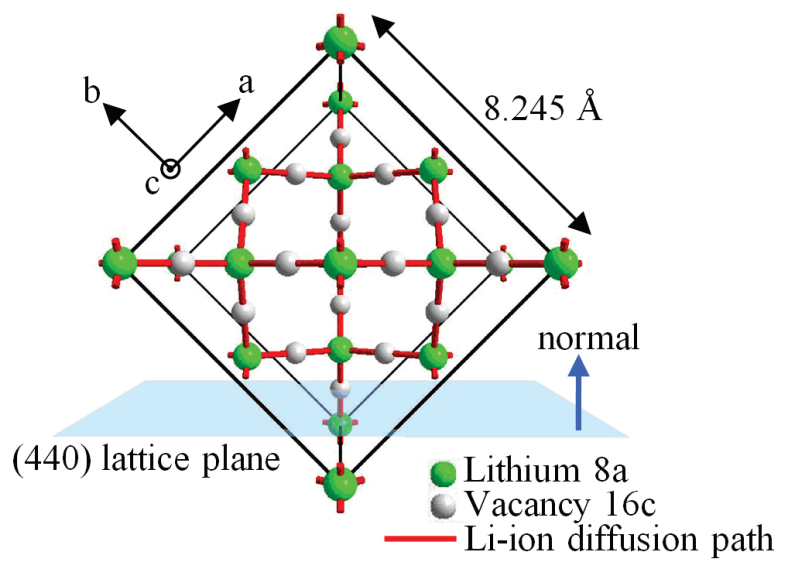

Fig. 7 Schematic view of a cross section through an ideal cubic lattice (space group: $\mathrm{Fd} 3 \mathrm{~m}$ ) of the $\mathrm{LiMn}_{2} \mathrm{O}_{4}$ spinel phase which shows the (440) lattice plane parallel to surface and resulting $\mathrm{Li}^{+}$sites (8a) with vacancies (16c) as well as $\mathrm{Li}^{+}$diffusion paths.

In order to validate the ability of Li-ion motion and diffusion within the achieved phase, electrochemical testing provides a powerful tool. Therefore, correlation in between 
CV measurements and galvanostatic testing may figure out the voltage plateaus and current peaks which indicate Liion diffusion mechanisms due to weak slopes within the dis-/charging curve or an increase in current. Such features are able to characterize the synthesized material. Before starting galvanostatic testing, CV measurements were carried out in order to determine an ideal voltage window for avoiding lithiation of the spinel compound below $3 \mathrm{~V}$ and therefore, phase transitions during cycling of the cathode [28] as well as accompanied chemical degradation effects such as unstable SEI formation on the cathode side and loss of active material due to chemical degradation of the electrode material $[9,14]$. Fig. 8 shows a cyclic voltammogram of a laser-annealed Li-Mn-O thin film in a voltage range of $2.5-4.3 \mathrm{~V}$.

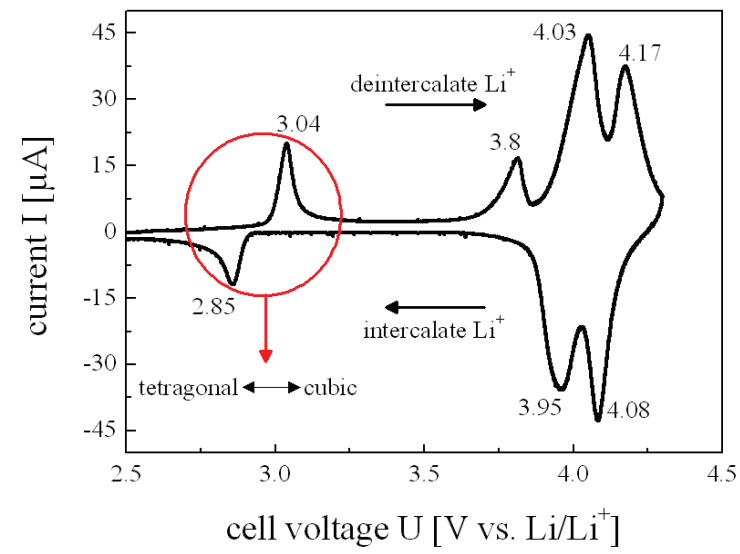

Fig. 8 Cyclic voltammogram of a laser-annealed Li-Mn-O thin film $\left(\lambda=940 \mathrm{~nm}, \mathrm{t}=100 \mathrm{~s}, \mathrm{~T}=680^{\circ} \mathrm{C}\right.$, laser scanning velocity $\mathrm{v}=1000 \mathrm{~mm} / \mathrm{s}$, ambient air) showing the characteristic redoxpeaks for Li-ion diffusion and de-/intercalation $(2.85 \mathrm{~V} / 3.04 \mathrm{~V}$, $4.05 \mathrm{~V} / 3.95 \mathrm{~V}, 4.17 \mathrm{~V} / 4.08 \mathrm{~V}$ ) and phase transition cubic $\leftrightarrow$ tetragonal (voltage window $2.5-4.3 \mathrm{~V}$, sweep rate $\mathrm{dV} / \mathrm{dt}=0.02 \mathrm{mV} / \mathrm{s}, 7 \mathrm{th}$ cycle). The directions of de-/intercalation of Li-ions into and out of the Li-Mn-O cathode within this measurement are marked with arrows.

The redox peaks $(3.95 \mathrm{~V} / 4.03 \mathrm{~V}$ and $4.08 \mathrm{~V} / 4.17 \mathrm{~V})$ in the $4 \mathrm{~V}$ region can be clearly identified and are quite sharp which indicates a well-crystallized and nano-crystalline structure [29]. Those peaks specify a two-step process for Li-ion de-/intercalation with a homogeneous phase $(3.95 \mathrm{~V} / 4.03 \mathrm{~V})$ and the coexistence of two cubic phases $(4.08 \mathrm{~V} / 4.17 \mathrm{~V})$ with different lattice constants [28] while the two-step-process is associated with Li-ion ordering on half of the tetrahedral $8 \mathrm{a}$ sites [30]. This is characteristic for stoichiometry spinel $\mathrm{LiMn}_{2} \mathrm{O}_{4}$ following Equations 2 and 3 [31-33]:

$$
\begin{aligned}
& \mathrm{LiMn}_{2} \mathrm{O}_{4} \leftrightarrow(1 / 2) \mathrm{Li}^{+}+(1 / 2) \mathrm{e}^{-}+\mathrm{Li}_{0.5} \mathrm{Mn}_{2} \mathrm{O}_{4} \\
& \mathrm{Li}_{0.5} \mathrm{Mn}_{2} \mathrm{O}_{4} \leftrightarrow(1 / 2) \mathrm{Li}^{+}+(1 / 2) \mathrm{e}^{-}+2 \lambda-\mathrm{MnO}_{2}
\end{aligned}
$$

At $3.8 \mathrm{~V}$ an oxidation peak can be observed. This peak might belong to the spinel structure but the reason for its appearance is still unknown [34]. On further decreasing the voltage below $3 \mathrm{~V}$, a third redox pair occurs $(2.85 / 3.04 \mathrm{~V})$ indicating the onset of a phase transition from cubic to te- tragonal [35] due to lithiation of the spinel [34] compound and therefore change in the average manganese oxidation state from $\mathrm{Mn}^{4+}$ to $\mathrm{Mn}^{3+}$. This reaction follows Eq. 4:

$$
\mathrm{Li}\left[\mathrm{Mn}^{3+/ 4+}\right]_{2} \mathrm{O}_{4}+\mathrm{Li}^{+}+\mathrm{e}^{-} \leftrightarrow \mathrm{Li}_{2}\left[\mathrm{Mn}^{3+}\right]_{2} \mathrm{O}_{4}
$$

This phase transition induces the onset of a global JahnTeller lattice distortion due to $>50 \%$ of $\mathrm{Mn}^{3+}$ ions [25] accompanied by different chemical reactions such as disproportionation effects, formation of surface near electrochemical inactive phases and dissolution of $\mathrm{MnO}$ into the electrolyte $[9,14]$. These degradation mechanisms lower the cell performance and are therefore, partially avoidable when cycling the cathode in between e.g. $3.0-4.2 \mathrm{~V}$.

Fig. 9 clearly indicates that such a phase transition can be avoided by reducing the operating voltage window of the electrochemical cell. $\mathrm{CV}$ gives evidence that near the $3.0 \mathrm{~V}$ region no phase transition from cubic to tetragonal occurs. Only the characteristic redox peaks for the above discussed two-step Li-ion de-/intercalation process occur, having their maxima at 3.93/4.05 $\mathrm{V}$ and 4.05/4.17 $\mathrm{V}$ which are in good agreement with the values reported in literature $[26,36]$. It should be noted, that also within a spinel-like compound the lattice constants differ within different stateof-charges (SOC) but those are cubic-to-cubic transitions [28]. In summary, features that can be investigated through $\mathrm{CV}$ are effects like degradation due to the lowering of the current density (area below each curve) with an increase in cycle number, evidence for SEI formation or lowering of the electric conductivity and consequently change in the Liion diffusion behavior and diffusion constant.

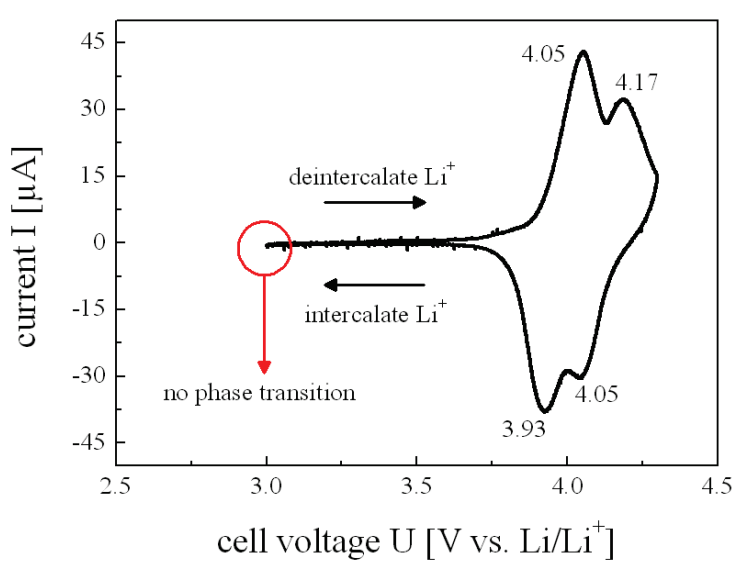

Fig. 9 Cyclic voltammogram of a laser-annealed Li-Mn-O thin film $\left(\lambda=940 \mathrm{~nm}, \mathrm{t}=100 \mathrm{~s}, \mathrm{~T}=680^{\circ} \mathrm{C}\right.$, laser scanning velocity $\mathrm{v}=1000 \mathrm{~mm} / \mathrm{s}$, ambient air) showing the characteristic redoxpeaks for $\mathrm{Li}^{+}$diffusion $(4.05 \mathrm{~V} / 3.93 \mathrm{~V}, 4.17 \mathrm{~V} / 4.05 \mathrm{~V})$ for a cubic spinel-like lattice structure (voltage window 3.0-4.3 V, sweep rate $\mathrm{dV} / \mathrm{dt}=0.02 \mathrm{mV} / \mathrm{s}$, 7th cycle). The directions of de/intercalation of Li-ions into and out of the Li-Mn-O cathode within this measurement are marked with arrows.

According to the $\mathrm{CV}$ results, the voltage window for galvanostatic testing was chosen to be $3.0-4.2 \mathrm{~V}$. Based on the measurements reported by Julien and Massot [8], cycling within this voltage range equals the extraction of $\sim 75-80 \%$ Li-ions out from the cathode host structure. This equals nearly $110 \mathrm{mAh} / \mathrm{g}$ for stoichiometric $\mathrm{LiMn}_{2} \mathrm{O}_{4}$. Within the assumption that laser-annealing leads to a spi- 
nel-like compound this value was used for calculation of the current for a $\mathrm{C} / 5$ rate $(\mathrm{I}=27.06 \mu \mathrm{A})$.

Fig. 10 describes the developing of the charging and discharging capacities in dependency of the cell voltage U. For capacity calculation both, the cathode area $\left(1.131 \mathrm{~cm}^{2}\right)$ as well as the film thickness $(2.7 \mu \mathrm{m})$ were taken into account. The second charging cycle shows a capacity of $38 \mu \mathrm{Ahcm}^{-2} \mu \mathrm{m}^{-1}$ while the discharge capacity was calculated to be about $30 \mu \mathrm{Ahcm}^{-2} \mu \mathrm{m}^{-1}$. The values of the charging and discharging plateaus of the second cycle (charging: $4.03 \mathrm{~V}, 4.15 \mathrm{~V}$, discharging: $4.05 \mathrm{~V}, 3.95 \mathrm{~V}$ ) fit very well to the current peaks of the CV measurements and are in good agreement with those reported in literature $[4,26]$.

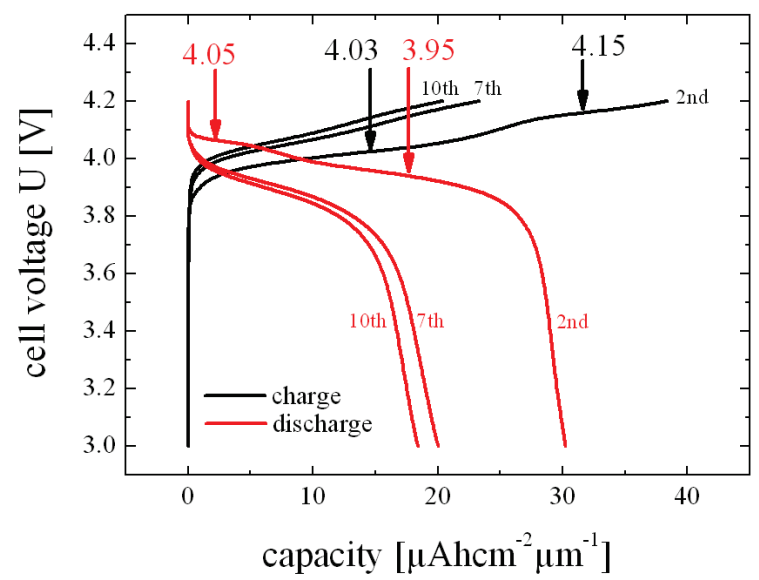

Fig. 10 Charging and discharging behavior of a laser-annealed $\mathrm{Li}-\mathrm{Mn}-\mathrm{O}$ thin film $\left(\lambda=940 \mathrm{~nm}, \mathrm{t}=100 \mathrm{~s}, \mathrm{~T}=680^{\circ} \mathrm{C}\right.$, laser scanning velocity $\mathrm{v}=1000 \mathrm{~mm} / \mathrm{s}$, ambient air) showing the $2 \mathrm{nd}$, 7 th and 10th cycle. Characteristic charging plateaus of the 2 nd cycle are marked with black arrows, discharging plateaus with red arrows.

On further cycling the cathode, the discharge capacity drops down to $18 \mu \mathrm{Ahcm}^{-2} \mu \mathrm{m}^{-1}$. It is supposed that JahnTeller effect can not be eliminated completely when cycling near the $3 \mathrm{~V}$ region and therefore, partial chemical degradation effects may play an important role as well as mechanical degradation due to volume changes during the Li-ion de-/intercalation process and subsequent thin film delamination. Therefore, to prevent mechanical degradation and to improve cycle stability the laser patterning process can be applied [2,10-14].

Fig. 11 shows the increase of cell voltage $U$ over the time $t$ for the second cycle. While the characteristic charging and discharging plateaus for the spinel compound can be clearly observed both, the charging as well as the discharging time does no reach the calculated value of 5 hours for each within the second cycle anymore.

In general, the parallel arrangement of the electrodes in lithium-ion batteries provides a 1-dimensional transport of lithium ions and therefore, to overcome power losses, the distance in between the electrodes is kept as small as possible, leading to the concept of thin film electrodes. Due to this fact, future cell designs will be based on 3-dimensional architectures [1]. One decisive role for the development of 3-dimensional electrode designs will play the laser patterning process in order to overcome power losses, inhomoge- neity of current densities and electric field effects. Besides the thin layered films defined surface structures lead to further enhancement of the active surface areas, higher area-to-volume ratios $(\mathrm{A} / \mathrm{V})$ and may provide more homogeneous current distributions. Regarding micro battery devices thin film Li-ion cells are preferred with thin film solid-state electrolytes such as LIPON [37] or Li-V-Si-O $[38,39]$. In order to investigate all-solid-state thin film batteries, rf magnetron sputtering and laser patterning processes were combined to demonstrate the feasibility of this concept. The goal is to apply PVD processes for setting-up thin film electrodes and to apply laser processes in a second step to form the 3-dimensional architecture.

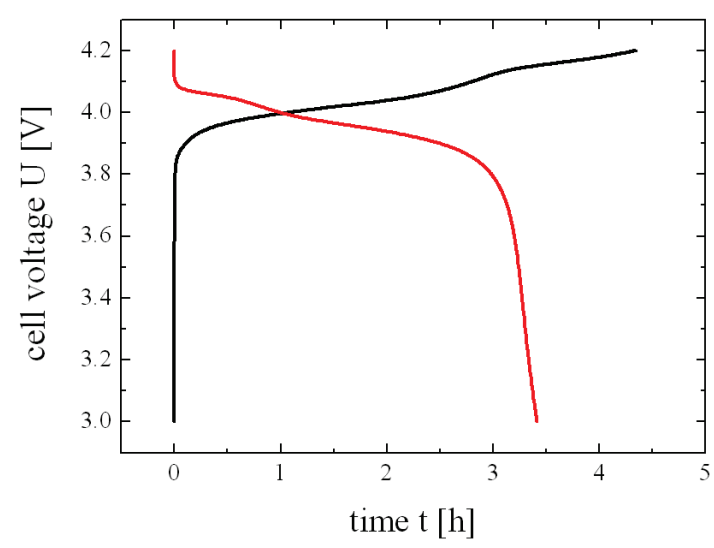

Fig. 11 Charging (black) and discharging (red) curve of a laserannealed Li-Mn-O thin film $\left(\lambda=940 \mathrm{~nm}, \mathrm{t}=100 \mathrm{~s}, \mathrm{~T}=680^{\circ} \mathrm{C}\right.$, laser scanning velocity $\mathrm{v}=1000 \mathrm{~mm} / \mathrm{s}$, ambient air) showing the 2 nd cycle and therefore, the cell voltage $U$ over half cycle time $t$.

Fig. 12 shows a cross-sectional Focused Ion Beam (FIB) image of the general set-up for this issue. First, a $3.3 \mu \mathrm{m}$ thick Li-Mn-O cathode (LMO) was sputtered on silicon. Silicon was chosen as the substrate in order to break the sample for cross-sectional views.

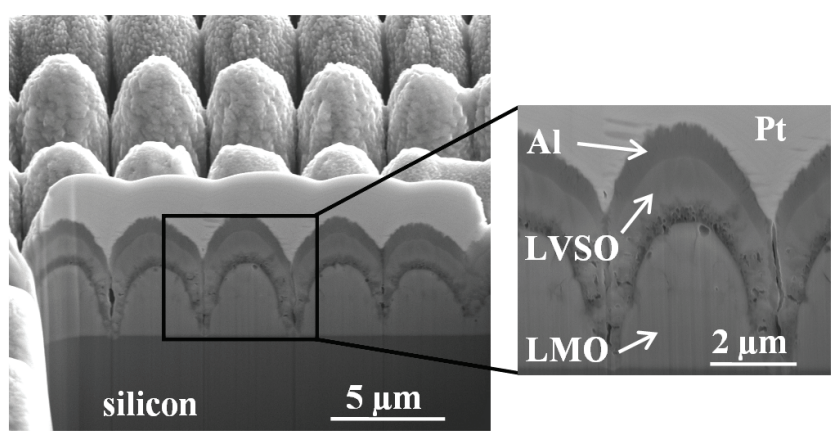

Fig. 12 Cross-sectional FIB image showing the principle set-up of a 3-dimensional all-solid state cell grown by rf magnetron sputtering sputtering of lithium vanadium silicon oxide (LVSO) electrolyte and aluminium (Al) anode material on top of the laser generated spherical lithium manganese oxide (LMO) structures. This layered model system was coated with platinum $(\mathrm{Pt})$ for enabling FIB measurements.

Within the laser patterning process 3-dimensional spherical surface structures were formed showing a small distance from structure to structure (see Fig. 2). In a third 
and fourth step, lithium vanadium silicon oxide (LVSO) used as solid electrolyte as well as aluminum (Al) were deposited on top of the surface structures with a maximum LVSO layer thickness of about $1.4 \mu \mathrm{m}$ and a maximum $\mathrm{Al}$ layer thickness of about $700 \mathrm{~nm}$. The challenge was to reach a complete coverage of these materials to the cathode and besides sporadic cracks this could be achieved in a first experimental approach. For the FIB procedure Platinum (Pt) was deposited on top of the 3D structures. The combination of laser patterning processes and rf magnetron sputtering might be a solution for overcoming problems of thickness limitations and disadvantages of 2-dimensional cell designs.

\section{Summary}

In this work direct laser patterning methods for fabrication of high-aspect and 3D microstructures in Li-Mn-O thin film cathodes were presented. It was shown that diffraction effects allow dimensions of about $400 \mathrm{~nm}$ which was significant below the objective resolution. Laserannealing of $\mathrm{Li}-\mathrm{Mn}-\mathrm{O}$ thin films at $680{ }^{\circ} \mathrm{C}$ formed a spinellike nano-crystalline phase with smaller grain sizes compared to extensive furnace annealing. Using X-ray diffraction for determining the crystalline structure is very complex for those thin films due to peak shifting. Yet a preferred (440) orientation could be achieved via laserannealing and was visualized with a schematic crosssectional lattice view. Via cyclic voltammetry electrochemical activity of the thin films was verified, also giving defined information about the synthesized thin film compound, the ability of the (440) texture for Li-ion diffusion as well as phase transitions during Li-ion de-/intercalation. Galvanostatic testing of the $\mathrm{Li}-\mathrm{Mn}-\mathrm{O} / \mathrm{Li}$ cell revealed the typical dis-/charging plateaus for a spinel-like structure in the $4 \mathrm{~V}$ region. Within this measurement a charging capacity of $38 \mu \mathrm{Ahcm}^{-2} \mu \mathrm{m}^{-1}$ and a discharging capacity of $30 \mu \mathrm{Ahcm}^{-2} \mu \mathrm{m}^{-1}$ were obtained for the second cycle showing low capacity retention on further cycling. Therefore, future galvanostatic testing will be done with laser patterned Li-Mn-O thin films for capacity stabilization using the same C-rate. In order to investigate all-solid-state 3D thin film batteries, the principal set-up of this design was tested with respect to the coverage and adhesion in between the layers using $\mathrm{Li}-\mathrm{Mn}-\mathrm{O}$ as cathode, $\mathrm{Li}-\mathrm{V}-\mathrm{Si}-\mathrm{O}$ as electrolyte and $\mathrm{Al}$ as an anode.

\section{Acknowledgments}

We would like to thank Nico Thiel for the sputtering of the thin films as well as Daniela Exner for carrying out FIB. We gratefully acknowledge the financial support by the Federal Ministry for Education and Research (BMBF) in the BMBF-project 03SF0344A "Li-ion battery cells based on novel nanocomposite materials" (LIB-NANO) in the framework of "Lithium-Ion Battery LIB-2015" and by the Helmholtz program NANOMIKRO. Finally, support by the Karlsruhe Nano Micro Facility (KNMF) for laser material processing is gratefully acknowledged.

\section{References}

[1] J.W. Long, B. Dunn, D.R. Rolison and H.S. White: Chem. Rev., 104, (2004) 4463-4492.

[2] R. Kohler, H. Besser, M. Hagen, J. Ye, C. Ziebert, S. Ulrich, J. Proell and W. Pfleging: Microsyst. Technol., 17, (2011) 225-232.

[3] H. Kim, R.C.Y. Auyeung and A. Piqué: J. Power Sources, 165, (2007) 413-419.

[4] S.N. Karthick, S.R.P. Gnanakan, A. Subramania and H.J. Kim: J. Alloys Compd., 489, (2010) 674-677.

[5] C. Wan, M. Wu and D. Wu: Powder Technol., 199, (2010) 154-158.

[6] Y.J. Park, J.G. Kim, M.K. Kim, H.G. Kim, H.T. Chung and Y. Park: J. Power Sources, 87, (2000) 69-77.

[7] C.M. Julien and M. Massot: Mater. Sci. Eng., B, 100, (2003) 69-78.

[8] C.M. Julien and M.A. Camacho-Lopez: Mater. Sci. Eng., B, 108, (2004) 179-186.

[9] K. Edström, T. Gustafsson and J.O. Thomas: Electrochim. Acta, 50, (2004) 397-403.

[10]R. Kohler, J. Proell, S. Ulrich, M. Przybylski and W. Pfleging: Proc. of SPIE 7921, San Francisco, (2011) p.79210P 1-11.

[11] R. Kohler, P. Smyrek, S. Ulrich, M. Bruns, V. Trouillet and W. Pfleging: J. Optoelectron. Adv. Mater., 12, (2010) 547-552.

[12]R. Kohler, J. Proell, S. Ulrich, V. Trouillet, S. Indris, M. Przybylski and W. Pfleging: Proc. of SPIE 7202, Bellingham, (2009) p.720207 1-11.

[13]R. Kohler, M. Bruns, P. Smyrek, S. Ulrich, M. Przybylski and W. Pfleging: Proc. of SPIE 7585, Bellingham, (2010) p.75850O 1-11.

[14] J. Proell, R. Kohler, C. Adelhelm, M. Bruns, M. Torge, S. Heißler, M. Przybylski, C. Ziebert and W. Pfleging: Proc. of SPIE 7921, San Francisco, (2011) p.79210Q $1-14$.

[15]A.C. Atre and C.B. Arnold: Proc. of SPIE 7921, San Francisco, (2011) p.792100 1-8.

[16]C. Ziebert, A. Knorr, N. Thiel, J. Fischer, R. Kohler, J. Proell, W. Pfleging, S. Ulrich and H.J. Seifert: Proc. of LiBD 5, Arcachon, (2011).

[17]B. Davis: Energeia, 5, (1994) 1, 4, 5.

[18] W. Pfleging, R. Kohler, M. Torge, V. Trouillet, F. Danneil and M. Stüber: Appl. Surf. Sci., (2011) doi:10.1016/j.apsusc.2011.02.126.

[19] C.M. Julien and M. Massot: Mater. Sci. Eng., B, 97, (2003) 217-230.

[20] S.H. Park, Y. Sato, J.K. Kim and Y.S. Lee: Mater. Chem. Phys., 102, (2007) 225-230.

[21] M.M. Thackeray, M.F. Mansuetto, D.W. Dees and D.R. Vissers: Mater. Res. Bull., 31, (1996) 133-140.

[22] J.M. Paulsen and J.R. Dahn: Chem. Mater., 11, (1999) 3065-3079.

[23] N. Kitamura, H. Iwatsuki and Y. Idemoto: J. Power Sources, 189, (2009) 114-120.

[24] JCPDS data base: Pdf\#350782.

[25]X.C. Tang, B.Y. Huang and Y.H. He: Trans. Nonferrous Met. Soc. China, 16, (2006) 438-444.

[26] J. Xie, T. Tanaka, N. Imanishi, T. Matsumura, A. Hirano, Y. Takeda and O. Yamamoto: J. Power Sources, 180, (2008) 576-581. 
[27]C.Z. Lu and G.T.K. Fey: J. Phys. Chem. Solids, 67, (2006) 756-761.

[28]K.Y. Chung and K.B. Kim: Electrochim. Acta, 49, (2004) 3327-3337.

[29] N. Kamarulzaman, R. Yusoff, N. Kamarudin, N.H. Shaari, N.a.A. Aziz, M.A. Bustam, N. Blagojevic, M. Elcombe, M. Blackford, M. Avdeev and A.K. Arof: J. Power Sources, 188, (2009) 274-280.

[30] S. Ma, H. Noguchi and M. Yoshio: J. Power Sources, 97-98, (2001) 385-388.

[31] Y.Y. Liang, S.J. Bao, B.L. He, W.J. Zhou and H.L. Li: J. Electrochem. Soc., 152, (2005) A2030-A2034.

[32] S.J. Bao, Y.Y. Liang and H.L. Li: Mater. Lett., 59, (2005) 3761-3765.

[33] J. Xie, K. Kohno, T. Matsumura, N. Imanishi, A. Hirano, Y. Takeda and O. Yamamoto: Electrochim. Acta, 54, (2008) 376-381.

[34] Y. Liu, X. Li, H. Guo, Z. Wang, Q. Hu, W. Peng and Y. Yang: J. Power Sources, 189, (2009) 721-725.

[35]C.J. Curtis, J. Wang and D.L. Schulz: J. Electrochem. Soc., 151, (2004) A590-A598.

[36]X. Li and Y. Xu: Electrochem. Commun., 9, (2007) 2023-2026.

[37] J.B. Bates, N.J. Dudney, G.R. Gruzalski, R.A. Zuhr, A. Choudhury, C.F. Luck and J.D. Robertson: Solid State Ionics, 53-56, (1992) 647-654.
[38] S. Zhao and Q. Qin: J. Power Sources, 122, (2003) 174-180.

[39]H. Ohtsuka and J. Yamaki: J. Appl. Phys., 28, (1989) 2264-2267.

(Received: June 3, 2011, Accepted: January 16, 2012) 